\title{
The oncofetal protein, 5T4, is a suitable target for antibody-guided anti-cancer chemotherapy with calicheamicin
}

\author{
E.R. BOGHAERT ${ }^{1}$, L. SRIDHARAN ${ }^{1}$, K.M. KHANDKE ${ }^{1}$, D. ARMELLINO ${ }^{1}$, M.G. RYAN ${ }^{2}$, K. MYERS ${ }^{2}$, R. HARROP ${ }^{2}$, \\ A. KUNZ ${ }^{3}$, P.R. HAMANN ${ }^{3}$, K. MARQUETTE ${ }^{4}$, M. DOUGHER ${ }^{1}$, J.F. DiJOSEPH ${ }^{1}$ and N.K. DAMLE ${ }^{1}$ \\ ${ }^{1}$ Wyeth Discovery Research (Oncology), Pearl River, NY, USA; ${ }^{2}$ Oxford BioMedica UK Ltd, Oxford, UK; \\ ${ }^{3}$ Wyeth Chemical and Screening Sciences, Pearl River, NY; ${ }^{4}$ Wyeth Biological Technologies, Cambridge, MA, USA
}

Received August 1, 2007; Accepted September 26, 2007

\begin{abstract}
The oncofetal protein, 5T4, is a tumor-associated protein displayed on the cell membrane of various carcinomas. This molecule is a promising target for anti-tumor vaccine development and for targeted therapy with staphylococcus exotoxin. The potential use of $5 \mathrm{~T} 4$ as a target for antibody-guided chemotherapy has not been demonstrated. We report oncolytic efficacy and selectivity in vitro and in vivo with immuno-conjugates of calicheamicin (CM) and the anti-5T4 antibody, H8. CM is a potent cytotoxic drug that causes double strand breaks in DNA. Conjugates of CM and $\mathrm{H} 8$ were constructed with acid-labile as well as acid-stabile linkers. In vitro, when applied to monolayers of $5 \mathrm{~T}^{+}$cells, CM-conjugates targeting 5T4 were consistently more toxic than either free drug or a non-binding control CM-conjugate. This difference was less pronounced on 5T4-deficient cells. In vivo, four 5T4-positive subcutaneous tumor models were treated with conjugates. Efficacy was demonstrated by reduction of tumor growth relative to controls treated with drug vehicle. To evidence selectivity, the efficacy of the anti-5T4 conjugates was compared to the efficacy of $\mathrm{H} 8$, a mixture of H8 and calicheamicin, calicheamicin alone or calicheamicin conjugated to the anti-CD33 antibody, hP67.6. In addition, the efficacy and selectivity of an acidlabile conjugate of $\mathrm{H} 8$ was evaluated in an orthotopic model for $5 \mathrm{~T}^{+}$lung cancer. Increased survival following treatment was used as a parameter of efficacy. Calicheamicin conjugates of $\mathrm{H} 8$ were effective and selective in all the examined tumor models. Differences in efficacy between the acid-labile and
\end{abstract}

Correspondence to: Dr Erwin Boghaert, Wyeth Research, Bldg 200, Room 4623, 401 North Middletown Road, 10965 Pearl River, NY, USA

E-mail: boghaee@wyeth.com

Key words: targeted chemotherapy, gemtuzumab ozogamicin, orthotopic, metastasis, xenograft acid-stabile conjugates depended on the investigated tumor model.

\section{Introduction}

Clinical efficacy of antibody-guided chemotherapy for acute myeloid leukemia was proven by the use of Mylotarg ${ }^{\circledR}$ (1). The strategy of antibody-guided chemotherapy entails the creation of an immuno-conjugate consisting of a potent cytotoxic agent linked to an antibody that selectively recognizes a tumor-associated antigen (TAA). The immunoconjugate improves the therapeutic index of the cytotoxic agent by delivering it to the tumor site whilst minimizing its exposure to normal tissues.

To date, applications of antibody-guided chemotherapy remain scarce (2) despite the seemingly straightforwardness of this approach on the one hand and the improved technology to manufacture non- or low-immunogenic antibodies on the other hand. The applications may not be readily forthcoming because TAAs suitable for antibody-guided chemotherapy are relatively rare. Indeed, to be considered as a suitable target, a molecule should satisfy several criteria $(3,4)$. The molecule has to be displayed on the surface of tumor cells. It should ideally be homogeneously expressed by the tumor cells and be absent in normal tissues and serum. Examples of molecules that approach these criteria are CD22 (5), Her2/neu (6), EGFR (7), PSMA (8), CEA (9), LewisY (10) and Tomoregulin (11).

To expand the application of antibody-guided chemotherapy, we investigated if the properties of oncofetal protein, 5T4, matched the requirements of a suitable target. 5T4 (also designated trophoblast glycoprotein, TPBG and M6P1) is a $72-80 \mathrm{kDa}$ transmembrane protein with an extensively $\mathrm{N}$-linked glycosylated core (12-14). Syncytiotrophoblasts in the placenta are virtually the only normal cells with high expression of 5T4. The antigen is virtually absent from normal adult cells. In contrast, immunohistochemical studies showed the presence of 5T4 on a variety of human tumors. 5T4 was found on carcinomas of the bronchi, breast, colon, rectum, stomach, cervix, endometrium, pancreas, ovaria and chorium (15-22). A direct relationship was established between the expression of 5T4 and the stage of gastric, colorectal and ovarian carcinomas (20-22). These results were obtained by using the mouse monoclonal antibody, $\mathrm{H} 8$. 
We used this antibody to identify tumor cell lines that expressed 5T4 and to determine internalization of the 5T4H8 complex. To verify efficacy and selectivity by targeting 5T4, several immuno-conjugate types of H8 and CM were made. N-Acetyl $\gamma$ calicheamicin dimethyl hydrazide (CalichDMH) and N-Acetyl $\gamma$ calicheamicin dimethyl acid (CalichDMA) were chosen as the CM derivatives for these conjugates. CalichDMH was used to generate acid-labile conjugates. An acid-stabile conjugate was made with CalichDMA. Efficacy of acid-stabile conjugates implies a necessary passage through the lysosomes and can therefore be seen as indirect evidence for internalization of the antigenconjugate complex (3).

The present work provides evidence that immunoconjugates targeting 5T4 selectively inhibit the growth of human $5 \mathrm{~T}^{+}+$tumor cells in vitro and induce a long lasting tumor growth inhibition of 5T4+ tumors in vivo. These effects in vivo were demonstrated on subcutaneous xenografts as well as on orthotopic lung carcinomas.

\section{Materials and methods}

Cells and culturing conditions. NCI-N87 (CRL-5822) and NCI-H157 (CRL-5802) were purchased from the American Type Culture Collection (ATCC, Manassas, VA). Cell lines obtained from ATCC were maintained in culture medium as specified by the supplier. PC14PE6 (23) and MDAMB435 were obtained from Dr I. Fidler (MD Anderson Cancer Center, Houston, TX). PC14PE6 cells were maintained in minimum essential medium supplemented with $10 \% \mathrm{v} / \mathrm{v}$ FBS, $2 \mathrm{mM}$ gln, $1 \mathrm{mM}$ sodium pyruvate, $0.2 \mathrm{mM}$ non-essential amino acids and 2\% MEM vitamin solution.

Generation of 5T4-transfected MDAMB435 cell lines. MDAMB435/5T4 are MDAMB435 cells that were transfected with a pIRES plasmid (Clontech, Mountainview, CA) encoding the human oncofetal protein, $5 \mathrm{~T} 4$ (Oxford BioMedica, Oxford, UK) and the neomycin resistance marker. MDAMB435 cells that were transfected with the pIRES vector encoding only the neomycin resistance marker were designated MDAMB435/neo. Fugene 6 (Roche Diagnostics, Indianapolis, IN) was used as the transfection reagent. Twenty-four hours following transfection, G418 (Invitrogen, Carlsbad, CA) was added at $1.5 \mathrm{mg} / \mathrm{ml}$. Resistant colonies were selected by ring cloning after a 1 week exposure to G418. MDAMB435/5T4 was isolated and established as a cell line after 2 cycles of limiting dilution cloning. MDAMB435/5T4 and MDAMB435/neo were maintained in minimum essential medium with Earle's salts supplemented with $10 \%$ v/v FBS, $2 \mathrm{mM}$ gln, $1 \mathrm{mM}$ sodium pyruvate, $0.2 \mathrm{mM}$ non-essential amino acids, $2 \%$ MEM vitamin solution and $0.5 \%$ pen $/$ strep and $1.5 \mathrm{mg} / \mathrm{ml} \mathrm{G} 418$.

Antigen and antibodies. Truncated recombinant 5T4 (5T4tmOxford BioMedica) was used as substrate to determine the affinity of anti-5T4 antibodies and conjugates by plasmon resonance analysis. 5T4tm lacks the transmembrane and intracellular domains of $5 \mathrm{~T} 4$. $\mathrm{H} 8$ is an $\mathrm{IgG}_{1} / \mathrm{kappa}$ mouse monoclonal antibody that was raised against placental 5T4 expressed on syncytiotrophoblasts.
hP67.6 (24) is a humanized $\operatorname{IgG}_{4}$ antibody that recognizes human CD33. For FACS-analysis, murine IgG (muIgG, Zymed, San Francisco, CA) and FITC-labeled goat antimuIgG (FITC/ $\alpha$-muIgG, Zymed, San Francisco, CA) were used as control antibody and as secondary antibody, respectively. Murine IgG (M198, Celltech, Slough, UK) and HRP conjugated goat anti-muIgG (Biorad, Hercules, CA) were the control and secondary antibodies used for Western blot.

PEGylation of H8. Several PEGylated versions of the H8 antibody were created to facilitate conjugation of NAc- $\gamma$ calicheamicin DMH (CalichDMH) to $\mathrm{H} 8$ antibody. H8PEG2K, H8PEG5K, H8PEGmal2 were synthesized as follows. The activated PEGs were obtained from Shearwater Corp (Huntsville, AL). PEG2K (cat\# 2M4M0D01, mPEG-SPA, MW 2,000), PEG5K (cat\# 2M450H01, mPEG-SBA, MW 5,000 ) and PEGmal2 (cat\# 2D2D0F02, PEG-bis-maleimide, MW 3,400) were all prepared at $100-200 \mathrm{mg} / \mathrm{ml}$ acetonitrile stock solutions stored at $-70^{\circ} \mathrm{C}$. The PEG2K and PEG5K were covalently bonded to lysines at PEG to antibody molar ratios of $4: 1$ to $3: 1$ for $3 \mathrm{~h}$ at $\mathrm{RT}$ followed by purification on Superose $610 / 30$ prior to calicheamicin conjugation. The H8PEGmal2 was covalently bonded to cysteines in two steps. The first was the relaxation of $\mathrm{H} 8$ with $20 \mathrm{mM}$ DTT for $1 \mathrm{~h}$ at RT and purification of the relaxed $\mathrm{H} 8$ on Superose 12 10/30. To the relaxed H8 was added the PEGmal2 in a molar ratio of $8: 1$. After $1 \mathrm{~h}$ at RT, the H8PEGmal2 was purified on Superose 12 10/30, followed by concentration on YM-50 and further purification of the concentrated protein on Superose $610 / 30$. The purified H8PEGmal2 was then conjugated with calicheamicin.

Calicheamicin conjugates and method of conjugation. Mylotarg ${ }^{\circledR}$ (CMA-676) is a calicheamicin conjugate produced by Wyeth. The carrier antibody hP67.6 recognizes CD33. The antibody was linked to CalichDMH with the 4-(4'acetylphenoxy)butanoic acid (AcBut) acid-labile linker. A batch with an average amount of $35 \mu \mathrm{g}$ calicheamicin conjugated to $1 \mathrm{mg}$ antibody was used.

The chemical procedures for conjugation were published earlier $(10,25)$. Briefly, conjugation of $\mathrm{N}$-acetyl $\gamma$ calicheamicin dimethyl hydrazide (CalichDMH) to $\mathrm{H} 8$ or PEGylated H8 was done by means of the acid-labile AcBut [4-(4'-acetylphenoxy) butanoic acid] or AcPAc [(3-acetylphenyl) acetic acid] linkers. The antibody at a protein concentration of approximately $10 \mathrm{mg} / \mathrm{ml}$ was adjusted to $\mathrm{pH}$ 8.0-8.5 with a high molarity non-nucleophilic buffer (1 M HEPES). Next, an excipient (sodium octanoate) that prevents protein aggregation was added at a final concentration of 0.1-0.2 M. Finally, 5\% of the protein mass of activated calicheamicin derivative was added as a concentrated solution $(10-20 \mathrm{mg} / \mathrm{ml})$ in an organic solvent (ethanol or dimethylformamide). This reaction mixture was then incubated at $25-35^{\circ} \mathrm{C}$ for $1-2 \mathrm{~h}$. Progress of the reaction was monitored by SEC-HPLC. After completion of the reaction, the conjugate was separated from aggregated antibody and free calicheamicin on a preparative SEC column.

Acid-stabile conjugates were obtained by linking $\mathrm{N}$-acetyl $\gamma$ calicheamicin dimethyl acid (CalichDMA) with an Amide 
(4-mercapto-4-methyl-pentanoic acid) linker to the antibodies. As in the reaction scheme given above, the antibody at a concentration of $\sim 10 \mathrm{mg} / \mathrm{ml}$ is adjusted to $\mathrm{pH} 8.0-8.5$ with 1-2 M non-nucleophilic buffer such as HEPES. To prevent aggregation and solubilize the calicheamicin during the reaction, a volume of organic solvent (DMF) is added to give a final concentration of $10-20 \%(\mathrm{~V}: \mathrm{V})$. The activated calicheamicin derivative (DMOSu) is added as a concentrated solution (10-20 mg/l) at an amount of $5 \%$ by weight of the protein mass. The reaction mixture is then processed as with the AcBut derivative.

Determination of the presence of $5 T 4$ in tumor cells and xenografts by Western blot analysis. Monolayers of cultured cells or tumor fragments were lysed by means of $0.5 \% \mathrm{v} / \mathrm{v}$ NP40 in 25 mM Tris-buffered saline at pH 7.4 (TBS). After protein estimation (Micro BCA ${ }^{\mathrm{TM}}$ Protein Assay Reagent Kit, Pierce, Rockford, IL), the lysates were mixed with Laemmli sample buffer (Biorad) and 1-10 $\mu \mathrm{g}$ samples were loaded in each well of a 4-20\% polyacrylamide gradient gel (Novex ${ }^{\circledR}$, Invitrogen). The samples were run for $2.3 \mathrm{~h}$ at $50 \mathrm{~mA}$ and transferred to a PVDF membrane by means of a Novex electrophoresis transfer system. The membrane was probed with H8, washed and reprobed with HRP conjugated goat anti-muIgG. The ECL detection system (Amersham, Buckinghamshire, UK) was used to visualize the presence of 5T4.

Determination of the presence of $5 T 4$ on tumor cells by FACS analysis. Aliquots of $10^{5}$ cells were suspended in $100 \mu 1$ phosphate-buffered saline supplemented with $1 \% \mathrm{w} / \mathrm{v}$ bovine serum albumin (PBS/BSA). The cells were then incubated at $4^{\circ} \mathrm{C}$ for $30 \mathrm{~min}$ in various concentrations of primary antibody: H8, H8PEG or H8 conjugates, as specified in the result section of this report. Binding of the primary antibody to the cells was revealed by FITC/ $\alpha-$ muIgG.

Determination of binding of $\mathrm{H} 8$ and conjugates to $5 T 4$ by plasmon resonance analysis (BIAcore). The recombinant extracellular domain of the 5T4 antigen $\left(5 \mathrm{~T} 4 \mathrm{tm}^{-}\right)$was immobilized to the surface of a CM5 biosensor chip at a density of 1,000 to 9,000 RU. The chip was activated by the coupling reagent EDC/NHS [1-ethyl-3-(3-dimethylaminopropyl)carbodiimide- $\mathrm{HCl}] /[\mathrm{N}$-hydroxysuccinimide] at a flow rate of $5 \mu \mathrm{l} / \mathrm{min}$ for $6 \mathrm{~min}$, followed by the addition of the $5 \mathrm{~T} 4 \mathrm{tm}^{-}$ antigen at 2 to $5 \mu \mathrm{l} / \mathrm{min}$ for 6-30 $\mathrm{min}$ at concentrations of 10 to $100 \mu \mathrm{g} / \mathrm{ml}$ in $10 \mathrm{mM}$ acetate buffer $\mathrm{pH} 4.0$ to 4.5 . Surplus binding sites were blocked with $1 \mathrm{M}$ ethanolamine$\mathrm{HCl}, \mathrm{pH} 8.5$, at $5 \mu \mathrm{l} / \mathrm{min}$ for $6 \mathrm{~min}$. Binding specificity analysis was performed in HBS-EP buffer (10 mM HEPES, $150 \mathrm{mM} \mathrm{NaCl}, 3 \mathrm{mM}$ EDTA, $50 \mathrm{ppm}$ polysorbate 20) at a flow rate of $20 \mu \mathrm{l} / \mathrm{min}$. H8 antibody, its PEG and CalichDMH conjugates were injected for $3 \mathrm{~min}$ at $6.67 \mathrm{nM}$ or $50 \mathrm{nM}$. The amount of antibody or conjugate that remained bound after a 30-sec wash with HBS-EP buffer was measured. The antigenic surface was regenerated by $10 \mathrm{mM}$ glycine, $\mathrm{pH} 1.5$, for $10 \mathrm{sec}$ followed by $10 \mathrm{mM}$ glycine $\mathrm{pH} 2.0$ for $30 \mathrm{sec}$, both at $30 \mu \mathrm{l} / \mathrm{min}$, to re-establish baseline. A stabilization time of 2 min was allowed prior to the injection of the next sample. The 5T4 antigen on the chip was coated at 1,000 to $1,500 \mathrm{RU}$ for determination of kinetic constants while it was 4,000 to $9,000 \mathrm{RU}$ for determination of plasma $\mathrm{H} 8$ concentrations for pharmacokinetics.

Determination of the efficacy of $5 T 4$ conjugates in vitro. The determination of an $\mathrm{ED}_{50}$ by means of a vital dye assay (MTS, Promega, Madison, WI) was described earlier (3). Briefly, 2,500 cells/well were seeded in 96-multi-well dishes. Immediately after seeding, the cells were exposed to various concentrations $(0,0.01,0.1,0.5,1,5,10,100$ and $500 \mathrm{ng} / \mathrm{ml})$ CM-equivalents of $\mathrm{CM}$ anti-5T4 conjugates, control conjugates or free CM. A CM-equivalent is the concentration $\mathrm{CM}$ given either as a pure substance or as a conjugate. After determination of the number of surviving cells following $96 \mathrm{~h}$ of exposure to conjugates or free drug, the $\mathrm{ED}_{50}$ was determined from the dose-response curves. The $\mathrm{ED}_{50}$ was defined as the concentration of drug that caused a $50 \%$ reduction of the cell number as compared to an untreated control. Dependent on the amount of CM bound to the antibody (antibody drug loading); a CM equivalent of different conjugates can imply different protein concentrations.

Efficacy of calicheamicin conjugates in vivo. Subcutaneous tumors were grown in athymic nude mice (Charles River, Wilmington, MA). Two-month-old female mice were injected with $5 \times 10^{6}$ MDAMB435/5T4 or N87cells. PC14PE6 and H157 cells were injected in male nude mice that were between 7 and 8 weeks old. To grow tumors, N87 and MDAMB435/ $5 \mathrm{~T} 4$ cells had to be mixed $(1: 1, \mathrm{v} / \mathrm{v})$ with Matrige ${ }^{\circledR}$ (Collaborative Biomedical Products, Belford, MA) prior to injection. Two perpendicular diameters of the tumor were measured by means of calipers at time intervals specified in the figures. The tumor volume was calculated according to the formula of Attia and Weiss (17): $\mathrm{A}^{2 *} \mathrm{~B}^{*} 0.4$. A and B are symbols for the smaller and the larger tumor diameter, respectively. The treatment schedules, dose and number of mice per group are specified in the result section and in the figure legends. All experiments with living animals were conducted conforming to PRACUC guidelines for humane treatment of animals.

Tumor growth inhibition $\left[\mathrm{I} \%=100^{*}(1-\mathrm{T} / \mathrm{C})\right]$ reflects reduction of the volume of treated tumors compared to controls. T stands for the average tumor volume of a group of mice that were treated with conjugate, free drug or antibody, and $\mathrm{C}$ is the average tumor volume of a vehicle control group. Both $\mathrm{T}$ and $\mathrm{C}$ were determined on the same day after treatment initiation. The sensitivity of the subcutaneous xenografts to any treatment was reflected by the maximum tumor growth inhibition $\left(\mathrm{I}_{\max } \%\right)$. This parameter is the maximum I-value observed during a given experiment.

Responses of individual mice to treatment were classified as stable disease (SD), limited progression (LP) and no response (NR). The sum of SD and LP represents the total fraction of mice with suppressed progression (SP). We concluded to SD when at the end of the observation period ( $\sim 100$ days) the tumor volume of the animal was smaller than the average tumor volume of its treatment group at onset of the treatment. LP was defined by the determination that at the end of the observation period a tumor had reached a volume that was less than double the average tumor volume of its treatment group at onset of the treatment. Mice with 
tumors larger than twice the average tumor volume of its treatment group at onset of the treatment were considered non-responders. When a mouse was euthanized because its tumor was either too large or too necrotic prior to the minimum observation period of 100 days, it was added to the NR fraction. A mouse was allocated to the SD group when it died after receiving three doses of any treatment and its tumor was smaller than the average tumor volume of its treatment group at onset of the treatment. In case a mouse died with a tumor larger than the average tumor volume of its treatment group at onset of the treatment, it was categorized as NR. Because the long observation period reduced the odds of survival of entire groups, we also report the non-tumor size related lethality (NTRL). NTRL represented the fraction of mice from any given group with an idiopathic death. The reported experiments were designed to reveal the anti-tumor efficacy of the various treatments and not to determine their toxic doses and regimens. The NTRL value is therefore only an indication of the number of animals lost in each group during the experiment. Significance of the difference in average tumor volume between two groups was determined by Student's t-test, taking into account the variance of the groups. We concluded to a significant difference when $\mathrm{p}<0.05$.

\section{Results}

Expression of $5 T 4$ by tumor cells in vitro and in vivo. The cell lines described in Table I expressed 5T4 consistently and were therefore chosen for further investigation. The MDAMB435 cell line displayed relatively the lowest levels of 5T4 (Fig. 1A) and was therefore selected as the acceptor cell line for transfection with the 5T4 expression vector. A clone expressing 200-fold more 5T4 (MDAMB435/5T4) relative to a mock-transfected clone (MDAMB435/neo) was used for further investigations (Fig. 1A and B). Also in vivo, MDAMB435/5T4 expressed 5T4 consistently (Fig. 1C). Consistent expression of 5T4 in vivo was also found in xenografted tumors of PC14PE6 and NCI-H157 (Fig. 1D). Variable expression of 5T4 was detected in NCI-N87 tumors. The expression of the antigen was found in 5/7 tumors.

In vitro efficacy and selectivity of anti-5T4 CM conjugates. The isogenic pair, MDAMB435/5T4 and MDAMB435/neo represented an ideal model for in vitro determination of target-selectivity of anti-5T4 CM conjugates for the following reasons. The different expression of 5T4 by these cell lines was readily detectable by FACS and Western blot. Variation of the 5T4 expression due to culture conditions (passage, confluence) was minimal (data not shown). Fig. 2A shows that bound $\mathrm{H} 8$-antibody gradually disappears from the membrane of MDAMB435/5T4 cells. Supernatants of these cell cultures did not contain reactive $\mathrm{H} 8$. This modulation of $\mathrm{H} 8$ as a function of time can therefore indicate internalization of the antigen-antibody complex. Table II summarizes the chemical composition of the anti-5T4 CM conjugates used for experimentation. As a means to overcome the low yield of producing AcBut-conjugated $\mathrm{H} 8$, the $\mathrm{H} 8$ antibody was PEGylated. However, these chemical modifications reduced the avidity of H8 (Table IIB). This loss of avidity was consistently demonstrated by plasmon resonance analysis and by flow cytometry. Fig. 2B summarizes the efficacy and selectivity of the conjugates described in Table II. Exposure of the monolayer cultures to CalichDMH allows a comparison of the sensitivity of the acceptor cell line and the transfectants. MDAMB435/5T4 and MDAMB435/neo are comparably sensitive to the free drug. The acceptor cell line is on average approximately twice as sensitive to $\mathrm{CM}$. This could indicate cross-resistance for neomycin and CM. Exposure of the monolayers to hP67.6-AcBut-CalichDMH controlled for the efficacy of CM by release of CalichDMH from the AcBut linker. $\mathrm{H} 8$ conjugated to $\mathrm{CM}$ via acid-labile linkers reduced $\mathrm{ED}_{50}$-values below those of CalichDMH and hP67.6-AcBut-CalichDMH in the three cell lines. This reduction was 50-fold lower in MDAMB435/5T4 than in MDAMB435/neo monolayers. Taken together, these findings not only indicate that the trace amount of 5T4 in MDAMB435/neo sufficed to allow targeted cytotoxicity but also that increasing the amount of 5T4 displayed on the cell membrane positively influenced this effect. Selective cytotoxicity was also demonstrated with the PEGylated conjugates. This selectivity was directly proportional to the avidity of the PEGylated $\mathrm{H} 8$ for 5T4 and evidenced further in favor of the involvement of 5T4 in enhancing the efficacy of the conjugate. The 200-fold increased efficacy of H8Amide-CalichDMA on MDAMB435/5T4 as compared to MDAMB435/neo (Fig. 2B and C) also supported the involvement of 5T4 in enhancing the efficacy of the conjugate. This finding also suggested internalization of the 5T4conjugate complex because the acid-stabile amide linker requires processing of the conjugate through the lysosomes to release $\mathrm{CM}$ (3).

Anti-5T4 calicheamicin conjugates inhibit tumor growth of MDAMB435 breast carcinoma cells transfected with $5 T 4$. The inhibition of tumor growth caused by calicheamicin conjugates of the anti-5T4 antibody, H8, or its PEGylated form, H8PEG(mal2), is illustrated in Fig. 3. H8 was conjugated to calicheamicin via either the acid-labile AcPAc or AcBut linkers (H8-AcPAc-CalichDMH or H8-AcButCalichDMH, respectively) or via the acid-stabile Amide linker (H8-Amide-CalichDMA). H8PEG(mal2) was conjugated to calicheamicin via the AcBut linker (H8PEG (mal2)-AcBut-CalichDMH). After subcutaneous injection of MDAMB534/ 5T4 cells, tumors were grown to a volume of $\sim 0.1 \mathrm{~cm}^{3}$. Three doses of the conjugates were administered intraperitioneally at $4 \mu \mathrm{g}$ calicheamicin per dose/mouse and with an interval of 4 days (Q4Dx3). The amount of conjugate was standardized according to the absolute amount of calicheamicin. Since calicheamicin is the active ingredient of the conjugate, expressing the dose as calicheamicin equivalent compensates for the differences in calicheamicin content of the various conjugates and allows a direct comparison of their efficacy. The loading ( $\mu \mathrm{g}$ calicheamicin per mg antibody) of calicheamicin conjugates used in the experiment depicted in Fig. 1 is as follows: H8-AcPAcCalichDMH $=25 \mu \mathrm{g} / \mathrm{mg}, \mathrm{H} 8-$ AcBut-CalichDMH $=15 \mu \mathrm{g} / \mathrm{mg}$, H8PEG(mal2)-AcBut-CalichDMH = $37.5 \mu \mathrm{g} / \mathrm{mg}$ and $\mathrm{H} 8$ Amide-CalichDMA $=24 \mu \mathrm{g} / \mathrm{mg}$. All the conjugates tested inhibited the growth of MDAMB534/5T4 significantly. Maximum inhibition rates caused by H8-AcPAc-CalichDMH, 
Table I. Expression of total 5T4 and 5T4 displayed on the cells surface as determined by Western blot and flow cytometry (FACS), respectively.

\begin{tabular}{lccccr}
\hline Cell line & \multicolumn{2}{c}{ Western blot } & \multicolumn{2}{c}{ FACS } \\
\hline & $\mathrm{N}^{+} / \mathrm{N}_{\mathrm{t}}$ & Intensity & Mean reMCF & Range reMCF & $\mathrm{N}_{\mathrm{d}}$ \\
\cline { 2 - 6 } MDAMB435 & $3 / 3$ & 1 & 2 & $1-3$ & 10 \\
PC14PE6 & $2 / 2$ & 2 & 6 & $5-6$ & 3 \\
NCI-H157 & $2 / 2$ & 3 & 9 & $6-10$ & 3 \\
NCI-N87 & $8 / 8$ & 4 & 7 & $7-8$ & 3 \\
\hline
\end{tabular}

$\mathrm{N}^{+} / \mathrm{N}_{\mathrm{t}}$ number of positive signals/number of independent determinations; intensity, relative rank order of the intensity; mean reMCF, average of $\mathrm{N}_{\mathrm{d}}$ independent determinations of the reMCF; reMCF, relative median channel fluorescence (MCF following staining with H8/MCF following staining with $\mathrm{mIgG}$ ).
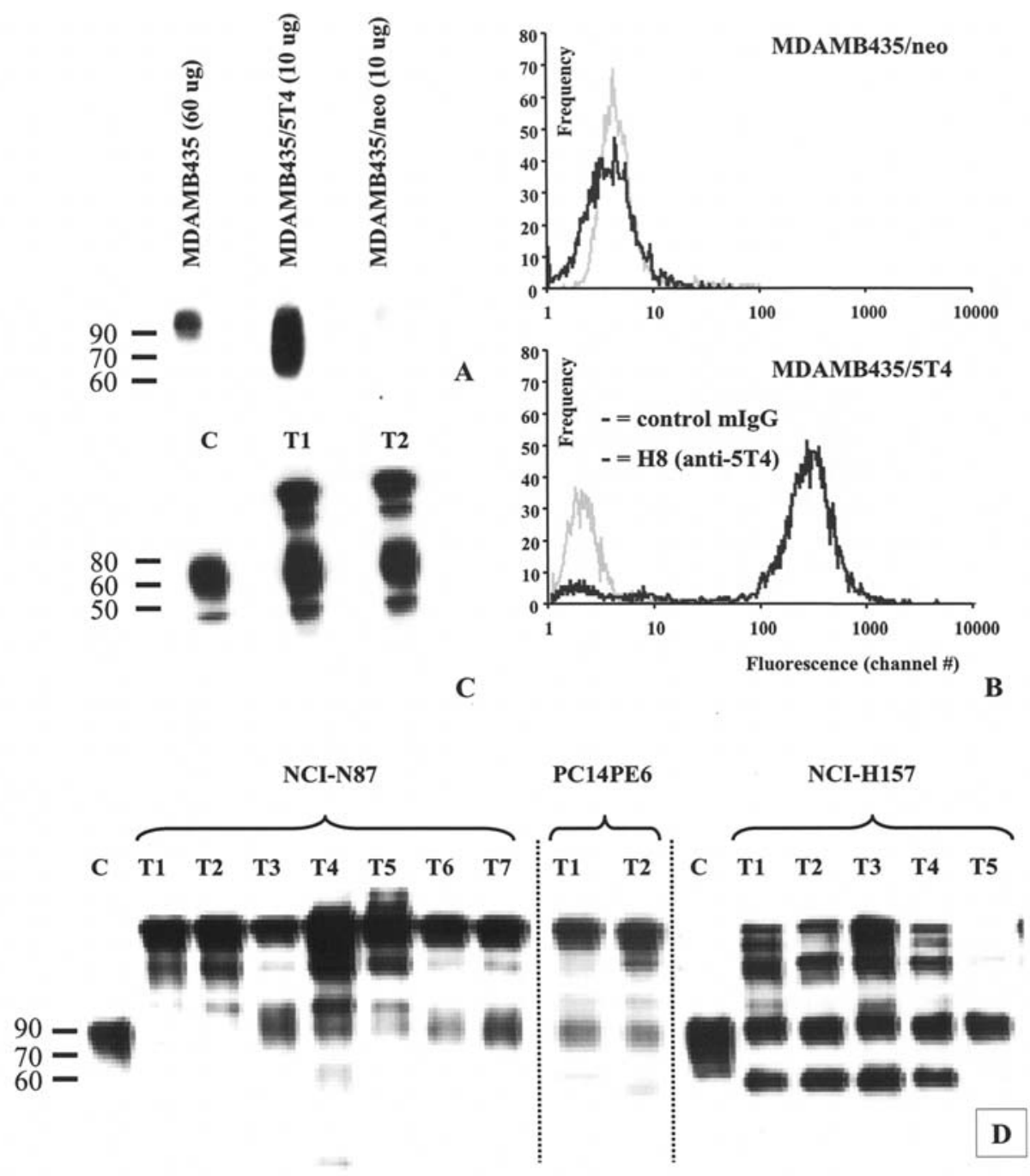

Figure 1. Expression of 5T4 by various tumor models. Protein extracts of MDAMB435 cells transfected with h5T4pIRES (MDAMB435/5T4) contain a fraction that is immunochemically revealed with the anti-5T4 antibody, H8. The Western blot in (A) shows a high intensity band between 70 and $90 \mathrm{kDa}$. The width of the band results likely from the heterogeneity in glycosylation of 5T4. This immunoreactive band was faint for protein extracts of the acceptor cell line (MDAMB435) or the mock-transfectant (MDAMB435/neo). MDAMB435/5T4 displayed approximately 200-fold more 5T4 as MDAMB435/neo as demonstrated by flow cytometry (B). (C) Illustrates that protein extracts of xenografted tumors of MDAMB435/5T4 (T1 and T2) also contained an intense immunoreactive fraction in the $60-90 \mathrm{kDa}$ range comparable to that found in extracts of the cell line $(\mathrm{C})$. Note that tumor extracts had additional immunoreactive fractions above $200 \mathrm{kDa}$. This is more likely caused by non-specific binding of the antibody to high molecular mass components than by cross-reactivity of the CDRs of the antibody since probing the gels with non-specific murine antibodies also revealed these fractions (data not shown). The Western blots (D) demonstrate the presence of the 5T4 antigen in xenografts of NCI-N87, PC14PE6 and NCI-H157. Ten $\mu \mathrm{g}$ protein of each tumor extract was loaded per lane. 


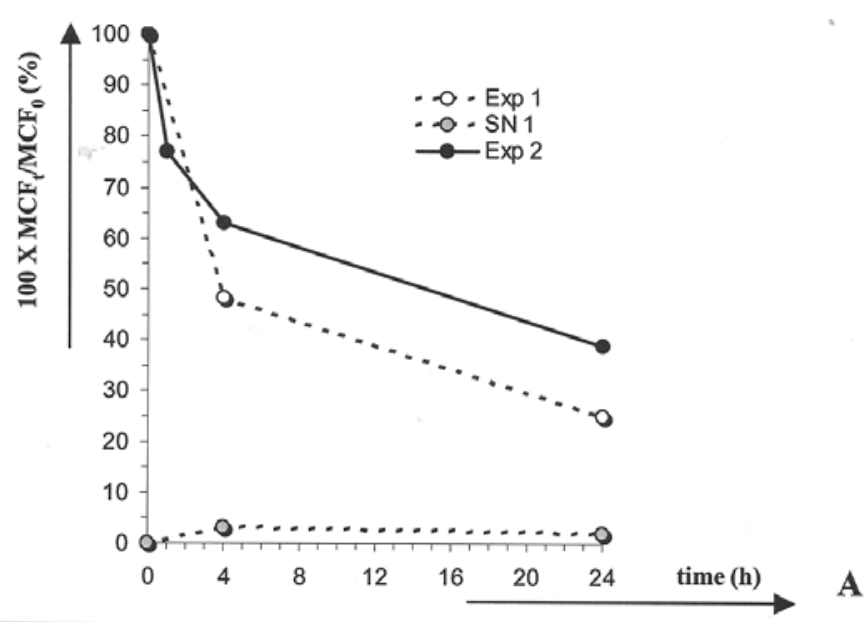

\begin{tabular}{|c|c|c|c|c|c|c|}
\hline \multirow[t]{2}{*}{ Conjugate } & \multicolumn{2}{|c|}{ MDAMB435 } & \multicolumn{2}{|c|}{ MDAMB435/neo } & \multicolumn{2}{|c|}{ MDAMB435/5T4 } \\
\hline & $\mathbf{E D}_{50} 0^{\mid \text {[a] }}$ & range & $\mathbf{E D}_{50}$ & range & $\mathbf{E D}_{50}$ & range \\
\hline CalichDMH & $3.80(4)^{[b]}$ & $0.70-7.00$ & $11.90(7)$ & $2.00-30.00$ & $10.50(6)$ & $5.00-20.00$ \\
\hline hP67.6-AcBut-CalichDMH & $41.00(3)$ & $23.00-70.00$ & $50.00(5)$ & $20.00-90.00$ & $55.00(4)$ & $20.00-80.00$ \\
\hline H8-AcBut-CalichDMH & $3.00(1)$ & $3.00-3.00$ & $2.30(1)$ & $2.30-2.30$ & $0.04(1)$ & $0.04-0.04$ \\
\hline H8-AcPAc-CalichDMH & n.d. & n.d. & $1.00(1)$ & $1.00-1.00$ & $0.02(1)$ & $0.02-0.02$ \\
\hline H8-Amide-CalichDMA & n.d. & n.d. & $40.00(1)$ & $40.00-40.00$ & $0.18(1)$ & $0.18-0.18$ \\
\hline H8PEG2K-AcBut-CalichDMH & $31.00(2)$ & $12.00-50.00$ & $41.50(2)$ & $23.00-60.00$ & $2.60(2)$ & $2.00-3.20$ \\
\hline H8PEGSK-AcBut-CalichDMH & $36.00(2)$ & $22.00-50.00$ & $45.00(2)$ & $40.00-50.00$ & $31.50(2)$ & $30.00-33.00$ \\
\hline H8PEGmal2-AcBut-CalichDMH & n.d. & n.d. & $7.00(1)$ & $7.00-7.00$ & $0.90(1)$ & $0.90-0.90$ \\
\hline
\end{tabular}

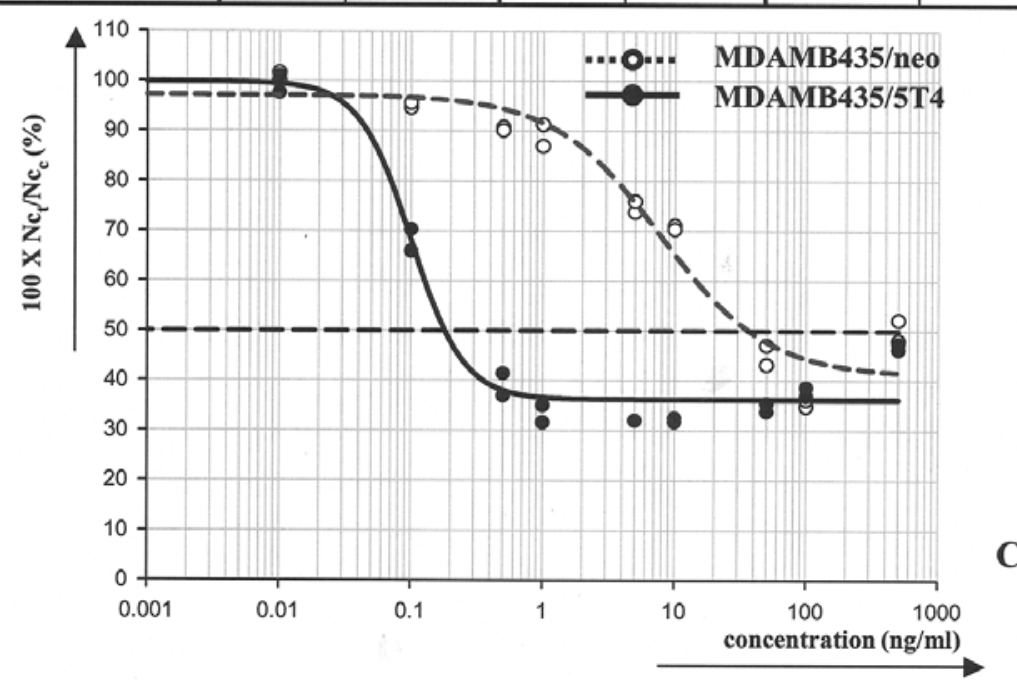

Figure 2. Internalization of the murine anti-5T4 antibody (H8) and selective cytotoxicity of its calicheamicin conjugates for cells with increased expression of 5T4. Disappearance of anti-5T4 antibody (H8) from MDAMB435/5T4 cells was monitored by FACS as a function of time (A) and expressed as a fraction of the initial signal $\left(\mathrm{MCF}_{\mathrm{t}} / \mathrm{MCF}_{0}\right)$. The figure depicts 2 experiments. For one experiment the supernatant was incubated with fresh cells to determine the amount of antibody released in the medium. $\mathrm{H} 8$ antibody was bound to MDAMB435/5T4 cells at $4^{\circ} \mathrm{C}$ and disappearance of the antibody from the cell surface was measured following incubation at $37^{\circ} \mathrm{C}$. (B) Shows average $\mathrm{ED}_{50}$ values for various calicheamicin conjugates of $\mathrm{H} 8$ and allows comparison to control conjugate and free calicheamicin. Selective cytotoxicity is indicated in grey. Cells cultured in monolayers were treated for $96 \mathrm{~h}$ and counted by means of a vital dye method (MTS). The $\mathrm{ED}_{50}$ [a] was defined as the concentration $(\mathrm{ng} / \mathrm{ml})$ of drug that caused a $50 \%$ reduction of the cell number as compared to an untreated control. The number shown in the table reflects the average of $\mathrm{n}[\mathrm{b}]$ independent determinations. The $\mathrm{ED}_{50} \mathrm{~s}$ were interpolated from logistic dose response curves as depicted in C. (C) indicates the loss of cells, as a fraction of the control (ordinate), after 4 days exposure of MDAMB435/5T4 and MDAMB435/neo to a concentration range (abscissa) of H8-Amide-CalichDMA. $\mathrm{Nc}_{\mathrm{t}}$ indicates the number of cells $96 \mathrm{~h}$ after treatment with the conjugate while $\mathrm{Nc}_{\mathrm{c}}$ indicates the number of cells $96 \mathrm{~h}$ after treatment with drug vehicle.

H8-AcBut-CalichDMH and H8-Amide-CalichDMA were similar: 99, 98 and $100 \%$, respectively. H8PEG(mal2)AcBut-CalichDMH was less efficacious $\left(\mathrm{I}_{\max }=77 \%\right)$ than the conjugates made from unmodified antibody. Combined with the observation that $\mathrm{H} 8 \mathrm{PEG}(\mathrm{mal} 2)$ had a reduced $(57 \%$ of H8, Table II) avidity for 5T4, the reduced efficacy of this conjugate in vivo suggest a role for binding of the conjugate to its targeting antigen for maximal tumor inhibition. The anti-tumor efficacy of 5T4-targeting conjugates was unambiguously demonstrated by the experiment illustrated by Fig. 3. However, selectivity of this efficacy for 5T4 was not demonstrated because only 5T4-targeted conjugates were 
Table II. Chemical properties of anti-5T4 antibodies, anti-5T4 conjugates and controls.

A

Name

Antibody

PEG

Linker $^{\mathrm{a}}$

CalichDMH

hP67.6-AcBut-CalichDMH

None

None

None

H8-AcBut-CalichDMH

hP67.6

None

AcBut

H8-AcPac-CalichDMH

H8

None

AcBut

H8-Amide-CalichDMA

$\mathrm{H} 8$

None

AcPAc

H8PEG2K-AcBut-CalichDMH

H8

None

Amide

H8PEG5K-AcBut-CalichDMH

$\mathrm{H} 8$

PEG2K

AcBut

H8PEGmal2-AcBut-CalichDMH

PEG5K

AcBut

$\mathrm{H} 8$

PEGmal2

AcBut

B

\begin{tabular}{|c|c|c|c|c|c|}
\hline Structure & Name & MW (kDa) & Abbreviation & \multicolumn{2}{|c|}{ Binding of H8PEG } \\
\hline & & & & Bb] \\
\hline & & & & & \\
\hline
\end{tabular}

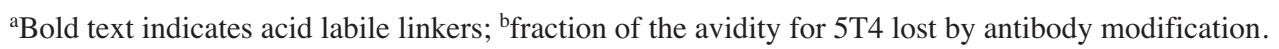

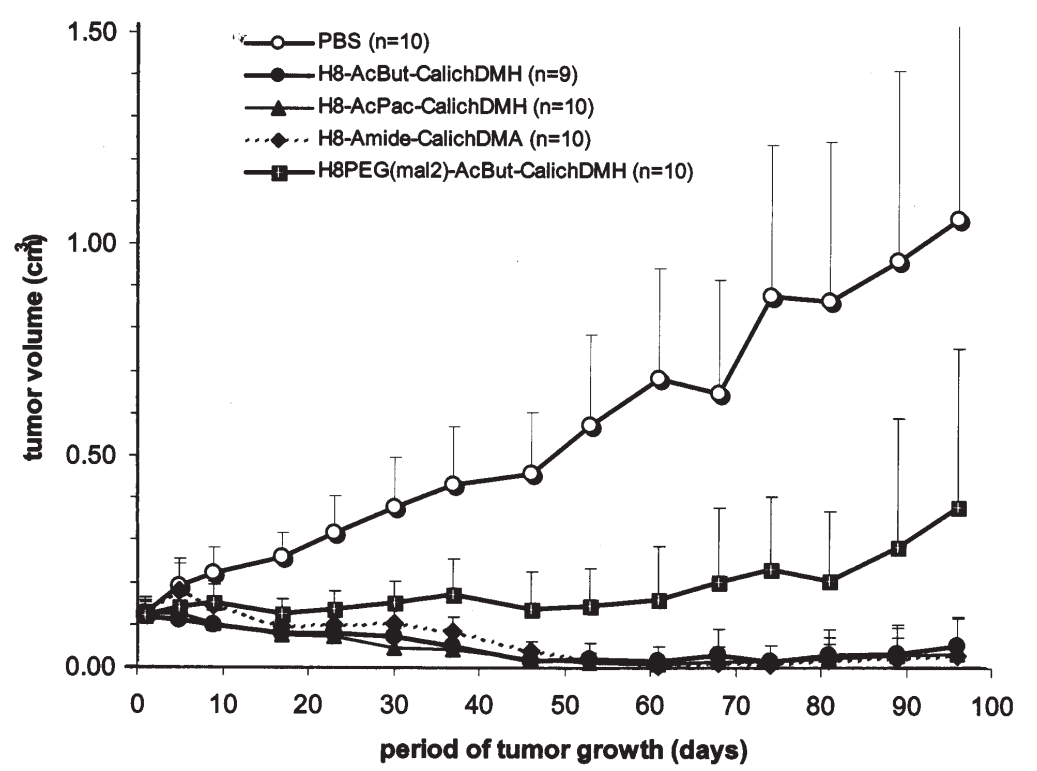

Figure 3. Inhibition of MDAMB435/5T4 subcutaneous tumor growth by 5T4-targeting calicheamicin conjugates. Anti-5T4 conjugates were injected intraperitoneally at a Q4Dx3 regimen when tumor volumes were $\sim 0.1 \mathrm{~cm}^{3}$. Calicheamicin $(4 \mu \mathrm{g})$ was administered per mouse per dose. The data points of each graph represent the average xenograft volumes of $n$ (specified in the legend) mice. Error bars represent the standard deviation of the tumor volumes in each group. PBS, vehicle control; H8-Amide-CalichDMA, 5T4-targeting calicheamicin conjugate with acid-stabile linker; H8-AcPAc-CalichDMH, 5T4targeting calicheamicin conjugate with AcPAc acid-labile linker; H8-AcBut-CalichDMH, 5T4-targeting calicheamicin conjugate with AcBut acid-labile linker; H8PEG(mal2)-AcBut-CalichDMH, 5T4-targeting calicheamicin conjugate of a PEGylated H8 antibody. 

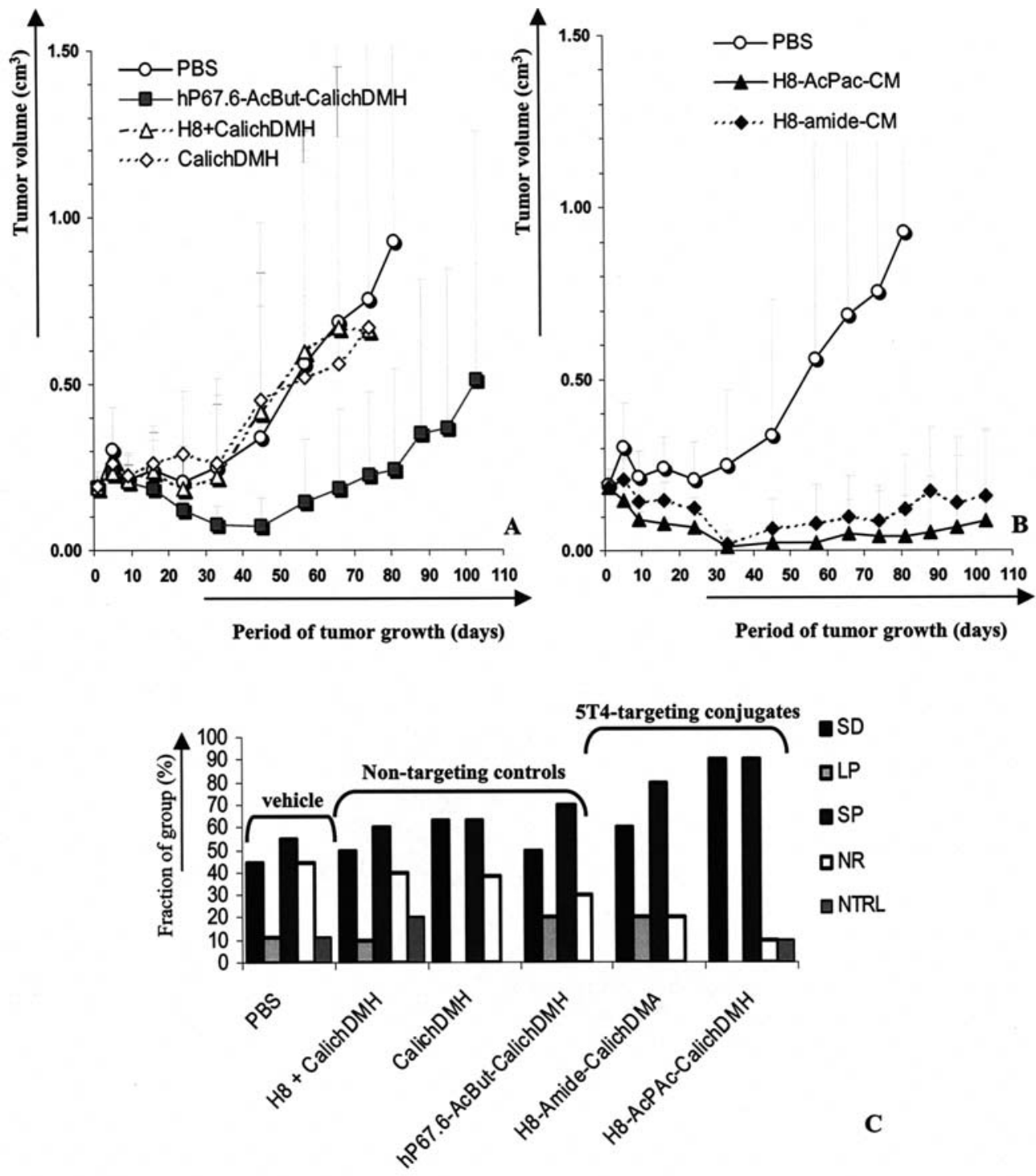

Figure 4. Comparison of growth inhibition of MDAMB435/5T4 subcutaneous tumors by free calicheamicin, a mixture of calicheamicin and a 5T4 targeting antibody, 5T4-targeting calicheamicin conjugates and a control calicheamicin conjugate. Treatment was administered intraperitoneally at a Q4Dx3 regimen when tumor volumes were $0.19 \mathrm{~cm}^{3}$ on average. Calicheamicin $(4 \mu \mathrm{g})$ was administered per mouse per dose. The data points and error bars of each graph represent respectively the averages and standard deviations of xenograft volumes. The number of mice (n) in each group is specified in the legend. The efficacy difference between controls (free calicheamicin, a mixture of calicheamicin and a 5T4 targeting antibody and a control calicheamicin conjugate, A) and 5T4-targeting calicheamicin conjugates (B) is presented. (C) Illustrates the efficacy of these treatments as disease status of individual mice after an observation period of 100 days. PBS, vehicle control; H8 + CalichDMH, mixture of anti-5T4 antibody and calicheamicin; CalichDMH, free calicheamicin; hP67.6-AcBut-CalichDMH, CD33-targeting calicheamicin conjugate; H8-Amide-CalichDMA, 5T4-targeting calicheamicin conjugate with acid-stabile linker; H8-AcPAc-CalichDMH, 5T4-targeting calicheamicin conjugate with acid-labile linker; SD, stable disease; LP, limited progression; SP, suppressed progression; NR, no response; NTRL, not tumor size related lethality.

used. The experiment shown in Fig. 4 compares the growth inhibition of MDAMB435/5T4 tumors by anti-5T4 conjugates to the efficacy of various controls. Fig. 4A demonstrates the lack of efficacy of a mixture of antibody and calicheamicin (H8 + CalichDMH) and of calicheamicin alone (CalichDMH). When this is contrasted to the anti-tumor efficacy obtained by administering H8-AcPAc-CalichDMH or H8-Amide-CalichDMA (Fig. 4B), one can conclude that conjugation of calicheamicin to the antibody is essential to obtain tumor growth inhibition. hP67.6-AcBut-CalichDMH causes significant growth inhibition of xenografts (Fig. 4A). This occurs despite the virtual lack of binding of either hP67.6 or hP67.6-AcBut-CalichDMH to MDAMB435/5T4 cells. Flow cytometry determined reMCF of $0.66(\mathrm{~s}=0.21$, $\mathrm{n}=7)$ and $0.80(\mathrm{~s}=0.13, \mathrm{n}=6)$ for hP67.6 and its calicheamicin conjugate, respectively. The anti-tumor efficacy caused by hP67.6-AcBut-CalichDMH is probably due to the accumulation of the antibody in tumor tissue followed by release of calicheamicin from the acid hydrolysable AcBut linker $(3,10)$. This 'passive targeting' of calicheamicin leads in most xenograft models to significant inhibition of tumor growth. However, the efficacy of 'passive targeting' of calicheamicin is usually distinguishable from that caused by antigen requiring 'active targeting'. In the latter case, the efficacy is at equivalent dose and regimen longer lasting than that caused by passive targeting. The experiment presented in Fig. 4 is consistent with this deduction. After treatment of MDAMB435/5T4 tumor-bearing mice with hP67.6-AcBut- 

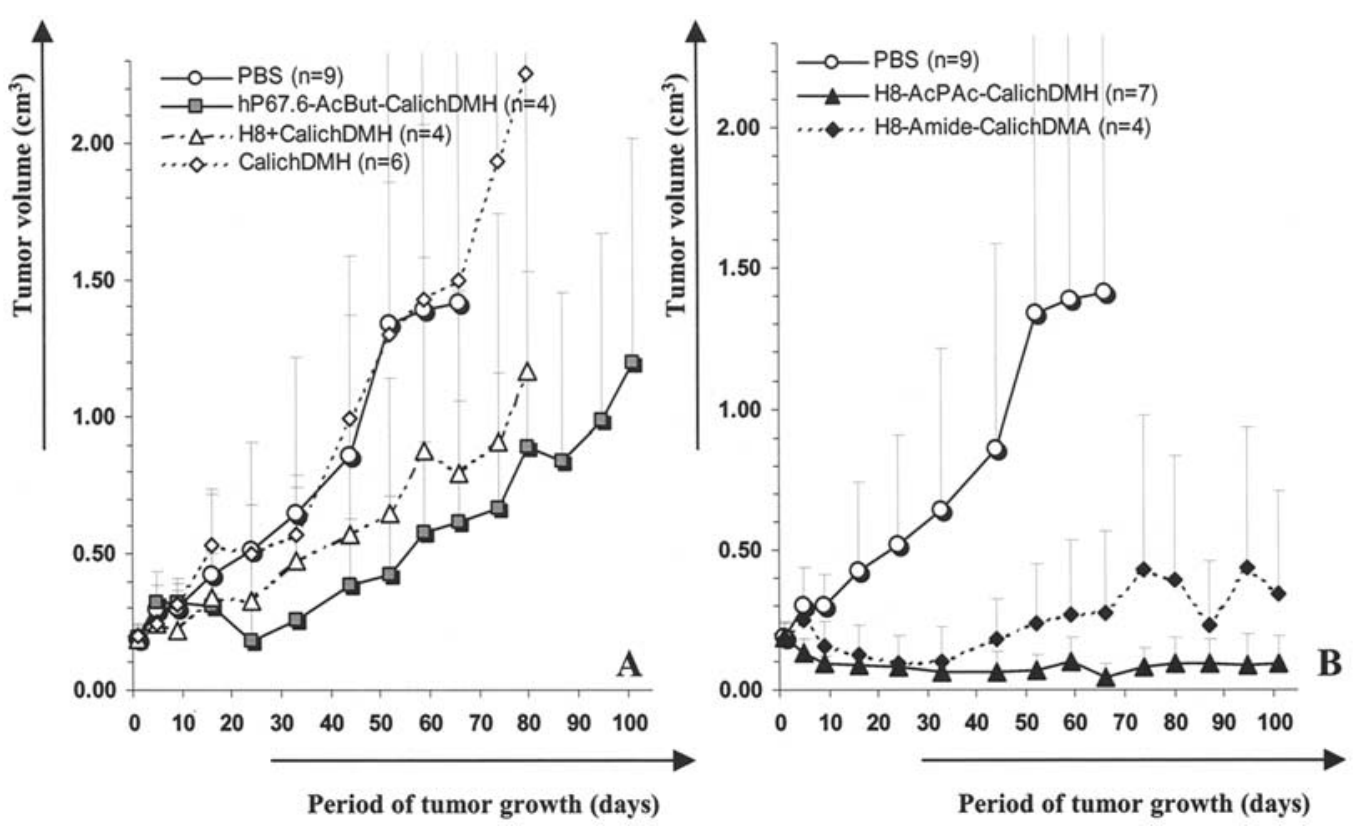

Figure 5. Comparison of growth inhibition of subcutaneous N87 tumors by free calicheamicin, a mixture of calicheamicin and a 5T4-targeting antibody, 5T4targeting calicheamicin conjugates and a control calicheamicin conjugate. Treatment was administered intraperitoneally at a Q4Dx3 regimen when tumor volumes were $\sim 0.2 \mathrm{~cm}^{3}$. Calicheamicin $(4 \mu \mathrm{g})$ was administered per mouse per dose. The data points and error bars of each graph represent respectively the averages and standard deviations of xenograft volumes. The number of mice (n) in each group is specified in the legend. The efficacy difference between controls (free calicheamicin, a mixture of calicheamicin and a 5T4 targeting antibody and a control calicheamicin conjugate, (A) and 5T4-targeting calicheamicin conjugates (B) is presented. The preparations of the anti-5T4 conjugates had a loading of 22-25 (H8-AcPAc-CalichDMH) and 29-35 $\mu \mathrm{g}$ (H8Amide-CalichDMH) calicheamicin per mg protein. H8 was administered at 160-182 $\mu$ g per dose per mouse. PBS, vehicle control; H8 + CalichDMH, mixture of anti-5T4 antibody and calicheamicin; CalichDMH, free calicheamicin; hP67.6-AcBut-CalichDMH, CD33-targeting calicheamicin conjugate; H8-AmideCalichDMA, 5T4-targeting calicheamicin conjugate with acid-stabile linker; H8-AcPAc-CalichDMH, 5T4-targeting calicheamicin conjugate with acid-labile linker.

CalichDMH, a significant ( $<<0.05$, Student's t-test, 2-tailed) tumor growth inhibition was observed from 23 to 34 days after the first dose. In contrast, growth was significantly inhibited following initiation of treatment with H8-AcPAcCalichDMH and H8-Amide-CalichDMA after 4 to 56 and after 15 to 32 days, respectively. Treatment with H8-AcPAcCalichDMH and H8-Amide-CalichDMA was significantly more efficacious after 15 to 34 days and on days 9 and 34 following initiation of treatment, respectively. Furthermore, 32 days following the first dose the Imax-values of H8AcPAc-CalichDMH and H8-Amide-CalichDMA were reached (96 and 92\%, respectively). In contrast, the Imax of hP67.6-AcBut-CalichDMH was only 78\% and observed 44 days after the first dose. It should be noted that 3 out of 9 mice in the group treated with PBS underwent spontaneous regression. This could explain that the growth inhibition caused by H8-AcPAc-CalichDMH and H8-Amide-CalichDMA was not significant beyond 56 and 32 days after initiation of the treatment. Nonetheless, as illustrated in Fig. 4C the number of mice with limited tumor progression (LP) or static tumors (SD) at 102 days following the initiation of treatment is higher after administration of the 5T4 targeting conjugates than with non-5T4-targeting controls. The highest $\mathrm{SD}$ response rate in this experiment was also noted after treatment with H8-AcPAc-CalichDMH. The anti-5T4 conjugates used for the experiment in Fig. 4 had a loading of 20-25 (H8-AcPAc-CalichDMH) and 29-35 $\mu \mathrm{g}$ (H8Amide-CalichDMA) calicheamicin per $\mathrm{mg}$ of protein. Control antibody was administered at 160 or $200 \mu \mathrm{g}$ per dose per mouse.
Anti-5T4 calicheamicin conjugates inhibit growth of tumors that originated from constitutively 5T4-expressing carcinoma cells. To verify that selective efficacy is not only possible in cells that display high amounts of 5T4, tumor inhibition of N87, H157 and PC14PE6 xenografts by anti-5T4 calicheamicin conjugates was studied. Fig. 5A illustrates the tumor growth of $\mathrm{N} 87$ gastric carcinoma cells after treatment with PBS, CalichDMH, a mixture of $\mathrm{H} 8$ and CalichDMH and a conjugate of calicheamicin and hP67.6. The Imax of hP67.6-AcBut-CalichDMH was in this experiment $68 \%$ at day 52. This inhibition was not statistically significant $(\mathrm{p}=0.07)$. Conceivably, variation within the group and the small number of animals $(n=4)$ treated with this conjugate was responsible for the high p-value. None of the other controls showed significant reduction of tumor growth as compared to the control treated with PBS. The Imax-values of tumors treated with CalichDMH or a mixture of $\mathrm{H} 8$ and CalichDMH were $8 \%$ (day $5, \mathrm{p}=0.43$ ) or $44 \%$ (day 66 , $\mathrm{p}=0.37)$, respectively. In comparison, the Imax-values after treatment with the anti-5T4 conjugates (Fig. 5B) were 97\% (H8-AcPAc-CalichDMH, day 66, p=0.02) and 84\% (H8Amide-CalichDMA, day 33, $\mathrm{p}=0.02$ ). This lower efficacy of the Amide-linked conjugate was also corroborated by a lower SP-rate $(50 \%, 2 / 4)$ as compared to that of the AcPAc-linked conjugate $(100 \%, 7 / 7)$. SP-rates after treatment with PBS, hP67.6-AcBut-CalichDMH, CalichDMH and a mixture of CalichDMH and H8 were 33, 25, 17 and 14\%, respectively. NTRLs were only observed in the groups treated with CalichDMH $(33 \%, 2 / 6)$ and H8-AcPAc-CalichDMH (14\%, 1/7). The experiment depicted in Fig. 5 shows that caliche- 


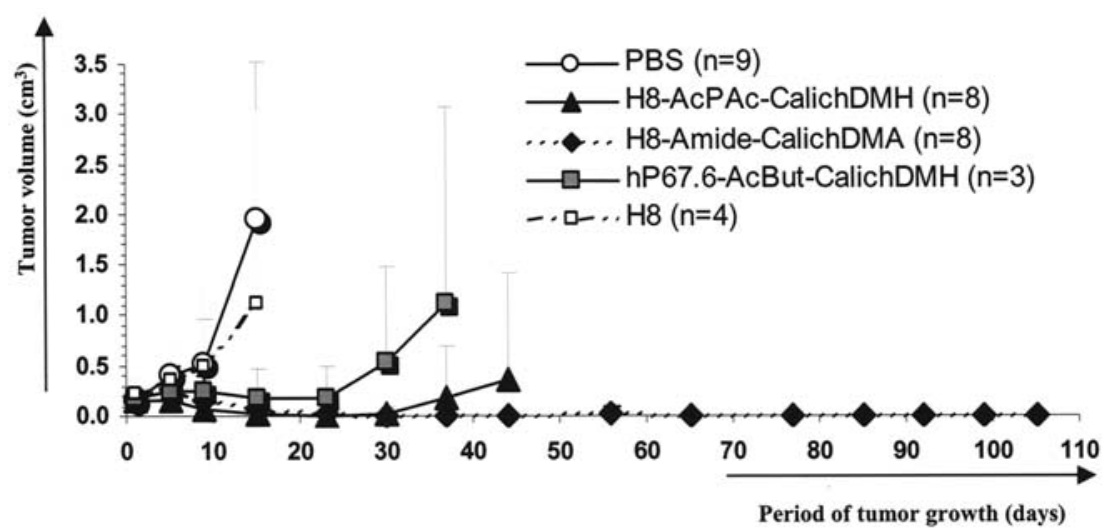

Figure 6. Comparison of growth inhibition of subcutaneous H157 tumors by a 5T4 targeting antibody, 5T4-targeting calicheamicin conjugates and a control calicheamicin conjugate. Treatment was administered intraperitoneally at a Q4Dx3 regimen when tumor volumes were $\sim 0.2 \mathrm{~cm}^{3}$. Calicheamicin (4) $\mu \mathrm{g}$ was administered per mouse per dose. The data points and error bars of each graph represent respectively the averages and standard deviations of xenograft volumes of $\mathrm{n}$ (specified in the legend) mice. The efficacy difference between controls (5T4 targeting antibody and a control calicheamicin conjugate) and 5T4-targeting calicheamicin conjugates is presented. The preparations of the anti-5T4 conjugates had a loading of 20 (H8-AcPAc-CalichDMH) and $29 \mu \mathrm{g}$ (H8-Amide-CalichDMH) calicheamicin per mg protein. H8 was administered at $200 \mu \mathrm{g}$ per dose per mouse. PBS, vehicle control; H8, anti-5T4 antibody; hP67.6-AcBut-CalichDMH, CD33-targeting calicheamicin conjugate; H8-Amide-CalichDMA, 5T4-targeting calicheamicin conjugate with acid-stabile linker; H8-AcPAc-CalichDMH, 5T4-targeting calicheamicin conjugate with acid-labile linker.
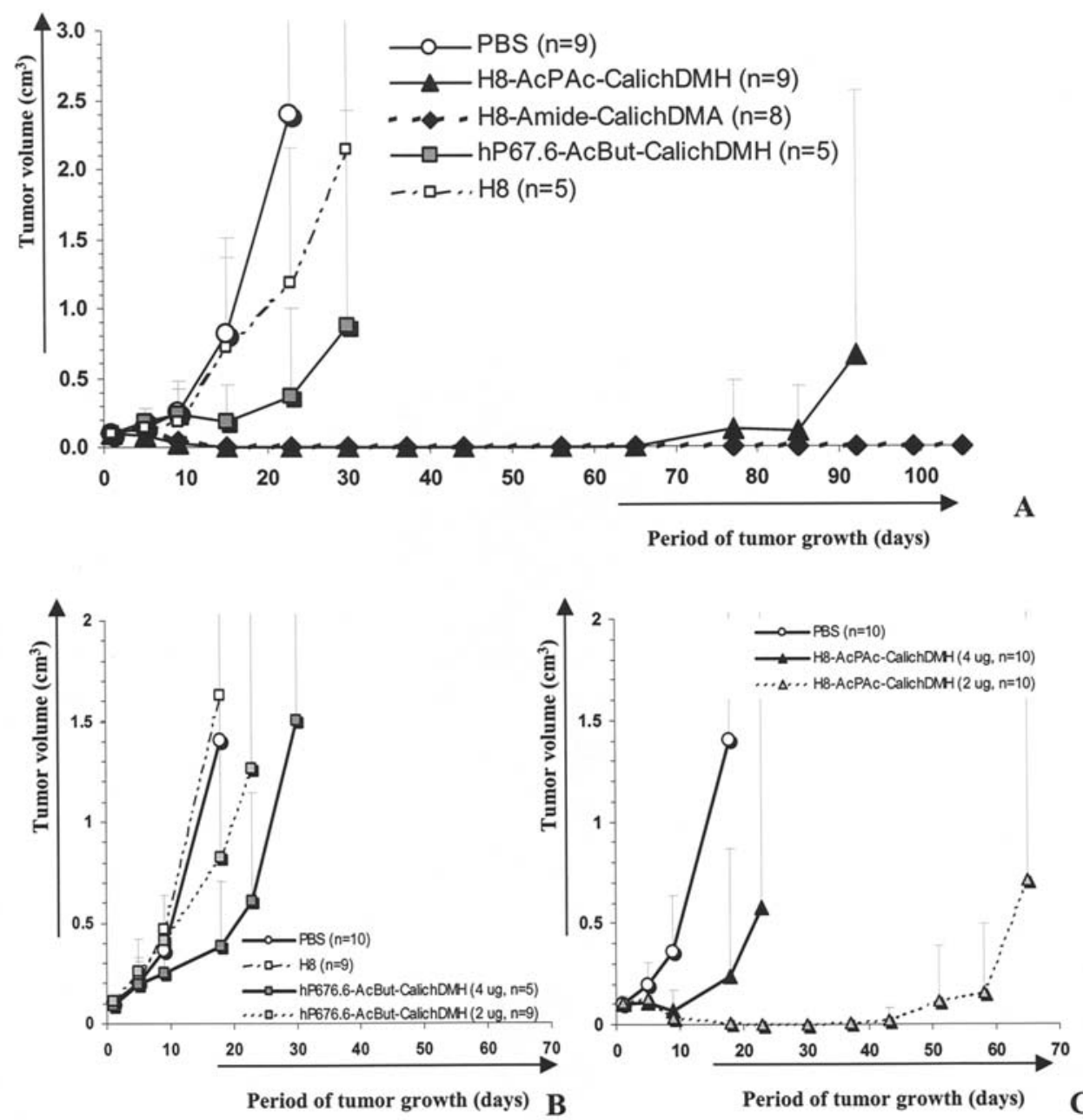

Figure 7. Comparison of growth inhibition of PC14PE6 subcutaneous tumors by a 5T4 targeting antibody, 5T4-targeting calicheamicin conjugates and a control calicheamicin conjugate. Treatment was administered intraperitoneally at a Q4Dx3 regimen when tumor volumes were $\sim 0.1 \mathrm{~cm}^{3}$. Calicheamicin (2 or $4 \mu \mathrm{g})$ were administered per mouse per dose. The data points and error bars of each graph represent respectively the averages and standard deviations of xenograft volumes of $\mathrm{n}$ (specified in the legend) mice. A first experiment (A) compared the efficacy of 5T4-targeting calicheamicin conjugates to controls (a 5T4-targeting antibody and a control calicheamicin conjugate). A second experiment compared the efficacy of a control conjugate (B) to 5T4-targeting calicheamicin conjugate (C). The preparations of the anti-5T4 conjugates had a loading of 20-22 (H8-AcPAc-CalichDMH) and $29 \mu \mathrm{g}$ (H8-AmideCalichDMH) calicheamicin per mg protein. H8 was administered at $200 \mu \mathrm{g}$ per dose per mouse. PBS, vehicle control; H8, anti-5T4 antibody; hP67.6-AcButCalichDMH, CD33-targeting calicheamicin conjugate; H8-Amide-CalichDMA, 5T4-targeting calicheamicin conjugate with acid-stabile linker; H8-AcPAcCalichDMH, 5T4-targeting calicheamicin conjugate with acid-labile linker. 

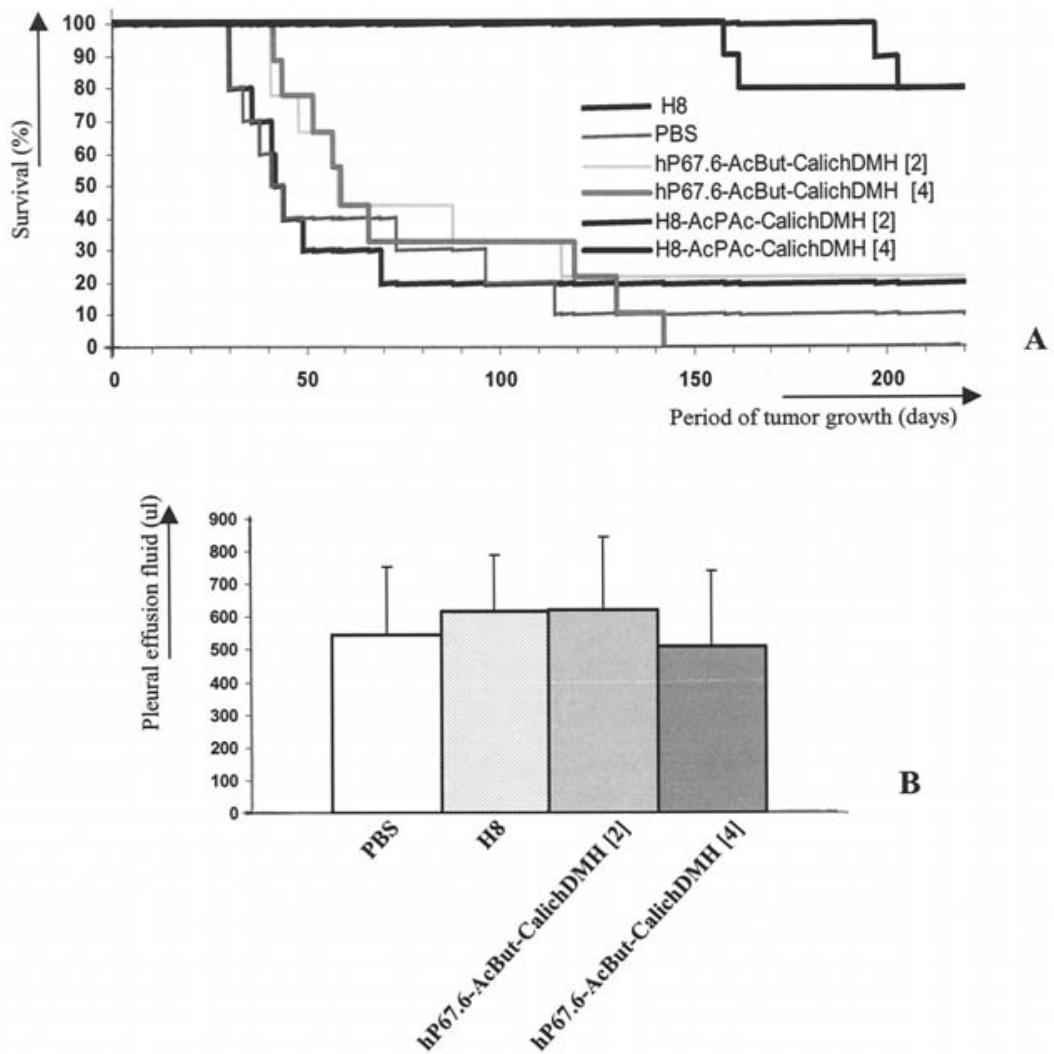

B

Figure 8. Inhibition of development of fatal lung carcinoma by an anti-5T4 calicheamicin conjugate (H8-AcPAc-CalichDMH). PC14PE6 cells were injected intravenously 6 days before treatment was administered intraperitoneally at a Q4Dx3 regimen. Calicheamicin ( 2 or $4 \mu \mathrm{g})$ was administered per mouse per dose (indicated between brackets in the legend). (A) Describes the fraction of surviving mice as a function of time. (B) Shows the volumes of pleural effusions measured upon death. The data points and error bars of each graph represent respectively the averages and standard deviations. The preparations of the anti-5T4 conjugates had a loading of 20 (H8-AcPAc-CalichDMH) $\mu \mathrm{g}$ calicheamicin per mg protein. H8 was administered at $200 \mu \mathrm{g}$ per dose per mouse. PBS, vehicle control; H8, anti-5T4 antibody; hP67.6-AcBut-CalichDMH, CD33-targeting calicheamicin conjugate; H8-AcPAc-CalichDMH, 5T4-targeting calicheamicin conjugate with acid-labile linker.

amicin conjugates targeting 5T4 inhibit N87 tumor-growth more effectively than a non-binding control conjugate, free antibody against 5T4 and free calicheamicin derivative.

Tumor growth-inhibition of H157 lung adenocarcinoma xenografts is illustrated in Fig. 6. H157 xenografts grew fast disallowing the survival of the majority of mice beyond 15 days after the first treatment with PBS or H8. At this time point, the Imax-values of treatment with H8, hP67.6-AcButCalichDMH, H8-AcPAc-CalichDMH and H8-AmideCalichDMA were 42, 91, 96 and 99\%, respectively. Inhibition caused by either H8 ( $\mathrm{p}=0.43$ ) or hP67.6-AcBut-CalichDMH $(p=0.09)$ was statistically significant. Nonetheless, the SPrates after these treatments were 67 and 50\%, respectively. In comparison, the tumor growth inhibition caused by either H8-AcPAc-CalichDMH or H8-Amide-CalichDMA was statistically significant ( $\mathrm{p}$-values $<0.01$ ). SP-rates after treatment with these conjugates were $63 \%(5 / 8)$ and $100 \%$ (7/7). NTRLs were only noticed in the H8-AmideCalichDMA $(13 \%, 1 / 8)$ and PBS $(11 \%, 1 / 9)$ treatment groups. Calicheamicin conjugates targeting $5 \mathrm{~T} 4$ inhibited H157 tumor-growth more effectively than a non-binding control conjugate and free antibody.

Similar results were obtained after testing the efficacy of anti-5T4 conjugates against PC14PE6 lung adenocarcinoma xenografts. Fig. 7A shows that H8-AcPAc-CalichDMH or H8-Amide-CalichDMA caused significant inhibition of tumor growth. The Imax-values of these conjugates were $100 \%$ and were reached after $14(\mathrm{p}<0.01)$ and 22 days $(\mathrm{p}=0.03)$, respectively. Imax-values after treatment with $\mathrm{H} 8(\mathrm{p}=0.26)$ or hP67.6-AcBut-CalichDMH $(\mathrm{p}=0.06)$ were 50 and $85 \%$, 22 days after the first dose. The SP-rates after treatment with H8-AcPAc-CalichDMH $(88 \%, 7 / 8)$ or H8-AmideCalichDMA $(100 \%, 8 / 8)$ were higher than following treatment with PBS $(33 \%, 3 / 9)$, H8 $(20 \%, 1 / 5)$ or hP67.6AcBut-CalichDMH $(25 \%, 1 / 4)$. NTRLs were observed in the groups treated with H8-AcPAc-CalichDMH $(11 \%, 1 / 9)$, H8 (40\%, 2/5) and hP67.6-AcBut-CalichDMH (20\%, 1/5).

Fig. 7B and $\mathrm{C}$ shows the differential response of PC14PE6 tumors to hP67.6-AcBut-CalichDMH (given Q4Dx3 at 2 or $4 \mu \mathrm{g} /$ mouse, Fig. 7B) and to H8-AcPAc-CalichDMH (given Q4Dx3 at 2 or $4 \mu \mathrm{g}$ /mouse, Fig. 7C). The response to hP67.6-AcBut-CalichDMH was more pronounced at a dose of $4 \mu \mathrm{g}(\operatorname{Imax}=73 \%$ at day 18, $\mathrm{p}=0.02)$ than at a dose of $2 \mu \mathrm{g}$ (Imax $=41 \%$ at day $18, \mathrm{p}=0.18$ ). Remarkably, using Imax as a parameter for comparison, the response to H8-AcPAcCalichDMH was inversely proportional to the amount of conjugate given. At a dose of $4 \mu \mathrm{g}$ the Imax was $83 \%$ (day $18, \mathrm{p}=0.02$ ) while at a dose of $2 \mu \mathrm{g}$ the Imax was $100 \%$ (day $18, \mathrm{p}<0.01)$. However, SP-rates after administration of 4 or $2 \mu \mathrm{g} \mathrm{H8}$-AcPAc-CalichDMH were $86(6 / 7)$ or $80 \%(8 / 10)$. The absence of a difference in efficacy after administering 2 or $4 \mu \mathrm{g}$ suggested that at a dose of $2 \mu \mathrm{g}$ the maximum anti- 
tumor efficacy was reached in the PC14PE6 tumor model. Regardless, the SP-rates after treatment with H8-AcPAcCalichDMH were higher than following treatment with PBS $(0 \%, 10 / 10), \mathrm{H} 8(0 \%, 9 / 9)$ or hP67.6-AcBut-CalichDMH at $2 \mu \mathrm{g}(0 \%, 9 / 9)$ or $4 \mu \mathrm{g}(0 \%, 5 / 5)$. NTRLs were only observed in the group treated with H8-AcPAc-CalichDMH at $4 \mu \mathrm{g}$ (30\%, 3/10 animals died before administration of the third dose).

Anti-5T4 calicheamicin conjugates inhibit development of lung tumors and pleural effusions in an orthotopic lung adenocarcinoma model. The PC14PE6 tumor cell line constitutes of a cell population from PC14 selected for its enhanced capacity to form pleural effusions following intravenous injection of a cell suspension in nude mice. Fig. 8 illustrates the survival rate of 6 groups of mice that were injected with $10^{6}$ PC14PE6 cells in the lateral tail vein. Mice were treated 6 days following the injection of tumor cells with PBS, H8 (200 $\mu \mathrm{g}$ per dose per mouse), H8-AcPAcCalichDMH (at a dose of either 2 or $4 \mu \mathrm{g}$ per mouse) and hP67.6-AcBut-CalichDMH (at a dose of either 2 or $4 \mu \mathrm{g}$ per mouse). Each treatment group consisted of 10 mice and the treatments were given at a Q4Dx3 regimen. In both groups treated with hP67.6-AcBut-CalichDMH, one mouse died before administration of third dose and without macroscopic indications of lung nodules or pleural effusion. These deaths were not recorded in the Kaplan and Meyer plot but were interpreted as reduction of the initial treatment group. As shown in Fig. 8A, the 50\% survival of the groups treated with antibody or PBS was 44 days. The groups that were treated with the control conjugate had a slightly prolonged survival with a $50 \%$ survival point between 56 and 59 days. The majority (97\%) of the deceased mice from these four treatment groups had macroscopic lung tumors. Most (30/32) of the tumor bearing animals had also developed measurable amounts of pleural fluid (Fig. 8B). One mouse treated with $4 \mu \mathrm{g}$ hP67.6-AcBut-CalichDMH died before termination of the experiment (day 114) without macroscopic signs of lung cancer. All the mice that were treated with H8-AcPAcCalichDMH survived 157 days after injection of the tumor cells. At this time, one mouse treated with $4 \mu \mathrm{g} / \mathrm{mouse}$ (Q4Dx3) of the anti-5T4 conjugate died. Necropsy revealed the presence of a large single lung nodule without evidence of pleural effusion. A second animal in this treatment group died at day 162. In this case the necropsy did not show any macroscopic evidence of lung tumor formation. The first dead mouse in the group treated with $2 \mu \mathrm{g}$ /mouse (Q4Dx3) of H8-AcPAc-CalichDMH was found at 197 days. Unfortunately, neither of the two mice that died before termination of the experiment at day 220 was pathologically examined. At day 220, all the remaining mice were sacrificed and necropsies were performed. At that time, none of the mice had macroscopic signs of lung cancer or pleural effusion.

\section{Discussion}

The presented preclinical study supports the notion that 5T4 can be a suitable target molecule for antibody-guided chemotherapy with CM. Various experimental conjugates targeting 5T4 were selectively cytotoxic for 5T4-expressing cells in vitro. In vivo, treatment with anti-5T4 CM conjugates inhibited tumor growth of 5T4-expressing xenografts more than treatment with free drug, a mixture of $\mathrm{H} 8$ and CM, H8 alone or a control conjugate.

The targeting antigen, 5T4, has previously been validated as a target for immunotherapeutic approaches against carcinomas. An anticancer vaccine strategy with a recombinant vaccinia virus expressing h5T4 [(human 5T4, (26,27)] implements this approach. Another therapeutic design using antibody-guided superantigen (Staphylococcus enterotoxin A) proved effective against 5T4 positive tumors in mice (28). The vaccine as well as the antibody-guided superantigen is currently being tested in a clinical setting (29-31). Appropriateness of $5 \mathrm{~T} 4$ as a target for immunotherapy was demonstrated by the induction of ADCC in vitro following exposure of anti-5T4 scFv-HIgG1 fusion protein to 5T4positive tumor cells (32). Choice of 5T4 as a target for these therapeutic strategies was based on the selective expression of the antigen on carcinoma tissues. Indeed, besides the syncythiotrophoblast layer in the placenta and a few specialized epithelia (e.g. esophagus and parotid gland), most adult tissues do not express the antigen. In contrast, the antigen is found on a wide variety of adenocarcinomas (19). The increased expression of 5T4 has also been associated with the disease stage for colorectal (20), gastric (21) and ovarian cancer (22). This emphasizes the value of 5T4 as a therapy target for late stage disease. The differential expression of 5T4 on normal and cancerous tissues is a necessary characteristic for the antitumor vaccine, superantigen strategy and antibody-guided chemotherapy. Success of immunotherapy targeted to 5T4 (i.e. superantigen and vaccine strategy) indicates that this antigen is present in sufficient amounts to be used for targeted delivery. This does not directly imply the validity of this target for targeted chemotherapy. For this form of therapy, the antigen ought not only to be displayed on the membrane but an internalization mechanism of the antigen-antibody complex would also be preferred. The benefit of using an internalizing antigen was shown for experimental immunoconjugates against EGFR (33), Her2/neu (34), CD22 (5) or PSMA (8). In contrast to those validated molecular targets, the knowledge about the physiological function and the cellular processing of 5T4 is not well established. Consistent with its tentative function in malignant progression, the antigen induces changes from epithelioid to a dendritic morphotype (35). These changes are indicative of increased mobility and are probably the result of downregulation of E-cadherin interactions. Both the intra- and extracellular domain of the antigen are involved in triggering these morphological changes (35). Because of the presence of the leucine rich regions in the extracellular domain a putative role of 5T4 in cell-matrix interaction is suspected. The physiological ligand of 5T4 remains nonetheless unknown. Awan et al (36) identified the PDZ domain containing GIPC as an intracellular binding partner for 5T4. GIPC has been implicated in trafficking of transmembrane proteins through the Golgi stacks (37-39). However, the association of GIPC to 5T4 at the membrane of a living cell has yet to be proven (37).

Our findings that $\mathrm{H} 8$ disappeared from the cell membrane and that $\mathrm{H} 8-\mathrm{CM}$ conjugates linked via the acid-stabile 
amide linker exerted selective efficacy in vitro indicated that internalization of the 5T4-H8 complex effectively allowed $\mathrm{CM}$ to reach its target. Furthermore, the efficacy in vitro of CM-conjugates did not only depend on the acid stability of the linker but also on the amount of antigen and the avidity of the antibody for the antigen. The $\mathrm{ED}_{50}$ of $\mathrm{H} 8-\mathrm{CM}$ conjugates constructed with an acid-labile linker was consistently lower in 5T4 overexpressing MDAMB435/5T4 cells than in MDAMB435/neo. It is noteworthy that the cytotoxity of these conjugates for MDAMB435/5T4 cells was higher than the efficacy of free calicheamicin. This finding suggests that targeting 5T4 facilitated transport of the conjugate.

The efficacy of CM-immunoglobulin conjugates in vivo is likely the result of a complex mixture of mechanisms. Calicheamicin conjugates targeting 5T4 significantly inhibited tumor growth of lung adenocarcinoma, gastric carcinoma and breast carcinoma xenografts. The 5T4targeting conjugates were more tumoricidal than antibody alone, free calicheamicin, a mixture of antibody and calicheamicin and a CD33-targeting control conjugate. This was indicated by using the maximum growth inhibition or response rates of individual mice as parameters of efficacy. The enhanced permeability and retention effect caused by the leaky vasculature of the tumor and subsequent release of free calicheamicin in the tumor insterstitium may in part explain (passive targeting, 3) the efficacy of conjugates constructed with acid-labile linkers. The tumoricidal effect of hP67.6AcBut-CalichDMH substantiated this possibility since the targeting antigen of this conjugate was not found in any of the tumors. Nonetheless, 5T4-targeting conjugates were consistently more efficacious suggesting that 5T4 could enhance the retention of an immunoconjugate after its initial accumulation in the tumor. The fact that a 5T4-targeting conjugate constructed with an acid-stabile linker was efficacious is an indirect argument for the internalization of the 5T4-H8 complex in tumor cells in vivo. Although not all the details of the working mechanism of a CM-conjugate in vivo have been elucidated, our findings clearly evidence that therapeutic benefit obtained by selectively targeting calicheamicin to 5T4. The efficacy of the 5T4 targeting conjugates was also demonstrated by arresting the development of lung adenoma carcinoma at the orthotopic location. Consequently, the cytoreductive effects of 5T4targeting calicheamicin conjugate was unlikely an artifact caused by treating heterotopic subcutaneous xenografts.

Taken together, the presented data demonstrate potent and selective cytoreductive efficacy by targeting calicheamicin immunoconjugates to tumors displaying the 5T4 antigen. The association of higher expression of the antigen with advanced disease and the restriction of its expression to malignant carcinomas underscores the potential benefit of targeting 5T4 with a calicheamicin conjugate.

\section{References}

1. Sievers EL, Appelbaum FR, Spielberger RT, et al: Selective ablation of acute myeloid leukemia using antibody-targeted chemotherapy: a phase I study of an anti-CD33 calicheamicin immunoconjugate. Blood 93: 3678-3684, 1999.

2. Schrama D, Reisfeld RA and Becker JC: Antibody targeted drugs as cancer therapeutics. Nat Rev 5: 147-159, 2006.
3. Boghaert ER, Khandke K, Sridharan L, et al: Tumoricidal effect of calicheamicin immuno-conjugates using a passive targeting strategy. Int J Oncol 28: 675-684, 2006.

4. Damle NK and Frost P: Antibody-targeted chemotherapy with immunoconjugates of calicheamicin. Curr Opin Pharmacol 3: 386-390, 2003.

5. DiJoseph JF, Armellino DC, Boghaert ER, et al: Antibodytargeted chemotherapy with CMC-544: a CD22-targeted immunoconjugate of calicheamicin for the treatment of B-lymphoid malignancies. Blood 103: 1807-1814, 2004.

6. Rosenblum MG, Shawver LK, Marks JW, Brink J, Cheung L and Langton-Webster B: Recombinant immunotoxins directed against the c-erb-2/HER2/neu oncogene product: in vitro cytotoxicity, pharmacokinetics and in vivo efficacy studies in xenograft models. Clin Cancer Res 5: 865-874, 1999.

7. Shao W, Zhao S, Liu Z, et al: Inhibition of human tumor xenograft growth in nude mice by a conjugate of monoclonal antibody LA22 to epidermal growth factor receptor with antitumor antibiotics mitomycin C. Biochem Biophys Res Commun 349: 816-824, 2006

8. Henry MD, Wen S, Silva MD, Chandra S, Milton M and Worland PJ: A prostate-specific membrane antigen-targeted monoclonal antibody-chemotherapeutic conjugate designed for the treatment of prostate cancer. Cancer Res 64: 7995-8001, 2004.

9. Cortez-Retamozo V, Backmann N, Senter PD, Wernery U, De Baetselier P, Muyldermans S and Revets H: Efficient cancer therapy with a nanobody-based conjugate. Cancer Res 64: 2853-2857, 2004.

10. Boghaert ER, Sridharan L, Armellino DC, et al: Antibodytargeted chemotherapy with the calicheamicin conjugate hu3S193-N-acetyl gamma calicheamicin dimethyl hydrazide targets Lewisy and eliminates Lewisy-positive human carcinoma cells and xenografts. Clin Cancer Res 10: 4538-4549, 2004

11. Zhao X-Y, Schneider D, Biroc SL, et al: Targeting tomoregulin for radioimmunotherapy of prostate cancer. Cancer Res 65: 2846-2853, 2005.

12. Hole N and Stern PL: A $72 \mathrm{kD}$ trophoblast glycoprotein defined by a monoclonal antibody. Br J Cancer 57: 239-246, 1988.

13. Hole $N$ and Stern PL: Isolation and characterization of 5T4, a tumour-associated antigen. Int J Cancer 45: 179-184, 1990.

14. Myers KA, Rahi-Saund V, Davison MD, Young JA, Cheater AJ and Stern PL: Isolation of cDNA encoding 5T4 ocofetal trophoblast glycoprotein. J Biol Chem 269: 9319-9324, 1994.

15. Kopreski MS, Benko FA and Gocke CD: Circulating RNA as a tumor marker. Detection of 5T4 mRNA in breast and lung cancer patient serum. Ann N Y Acad Sci 945: 172-178, 2001.

16. Starzynska, T, Marsh PJ, Schofield PF, Roberts SA, Myers KA and Stern PL: Prognostic significance of 5T4 oncofetal antigen expression in colorectal carcinoma. Br J Cancer 69: 899-902, 1994.

17. Jones H, Roberts G, Hole N, McDicken IW and Stern PL: Investigation of expression of 5T4 antigen in cervical cancer. Br J Cancer 61: 96-100, 1990.

18. Mieke W, Mulder C Stern PL, et al: Low intercellular adhesion molecule 1 and high 5T4 expression on tumor cells correlate with reduced disease-free survival in colorectal carcinoma patients. Clin Cancer Res 3: 1923-1930, 1997

19. Southall PJ, Boxer GM, Bagshawe KD, Hole N, Bromley M and Stern PL: Immunohistochemical distribution of 5T4 antigen in normal and malignant tissues. Br J Cancer 61: 89-95, 1990.

20. Starzynska T, Rahi V and Stern PL: The expression of 5T4 antigen in colorectal and gastric carcinoma. B J Cancer 66: 867-869, 1992.

21. Naganuma H, Kono K, Mori Y, Takayoshi S, Stern PL, Tasaka K and Matsumoto Y: Oncofetal antigen 5T4 expression as a prognostic factor in patients with gastric cancer. Anticancer Res 22: 1033-1038, 2002.

22. Wrigley E, McGown AT, Rennison J, Swindell R, Crowther D, Starzynska T and Stern PL: 5T4 Oncofetal antigen expression in ovarian carcinoma. Int J Gynaecol Cancer 5: 269-274, 1995.

23. Yano S, Nokihara H, Hanibushi M, Parajuli P, Shinohara T, Kawano $\mathrm{T}$ and Sone S: Model of malignant pleural effusion of human lung adenocarcinoma in SCID mice. Oncol Res 9: 573-579, 1997.

24. Hamann P, Hinman L, Hollander I, et al: Gemtuzumab ozogamicin, a potent and selective anti-CD33 antibody-calicheamicin conjugate for treatment of acute myeloid leukemia. Bioconjug Chem 13: 47-58, 2002. 
25. DiJoseph JF, Popplewell A, Tickle S, et al: Antibody-targeted chemotherapy of B-cell lymphoma using calicheamicin conjugated to murine or humanized antibody against CD22. Cancer Immunol Immunother 54: 11-24, 2005.

26. Mulryan K, Ryan MG, Myers KA, et al: Attenuated eecombinant vaccinia virus expressing oncofetal antigen (tumorassociated antigen) 5T4 induces active therapy of established tumors. Mol Cancer Ther 1: 1129-1137, 2002.

27. Ali S, Mulryan K, Taher T and Stern PL: Immunotherapy success in prophylaxis cannot predict therapy: prime-boost vaccination against the 5T4 oncofoetal antigen. Cancer Immunol Immunother 56: 165-180, 2007.

28. Rosendahl A, Kristensson K, Hansson J, Ohlsson L, Kalland T and Dohlsten M: Repeated treatment with antibody-targeted superantigens strongly inhibits tumor growth. Int J Cancer 76: 274-283, 1998 .

29. Harrop R, Connolly N, Redchenko I, et al: Vaccination of colorectal cancer patients with modified vaccinia Ankara delivering the tumor antigen 5T4 (TroVax) induces immune responses which correlate with disease control: a phase I/II trial. Clin Cancer Res 12: 3416-3424, 2006.

30. Forsberg, GOL, Brodin T, Bjork P, Lando P A, Shaw D, Stern PL and Dohlsten M: Therapy of human non-small-cell lung carcinoma using antibody targeting of a modified superantigen. Br J Cancer 85: 129-136, 2001.

31. Shaw DM, Connolly NB, Patel PM, et al: A phase II study of a 5T4 oncofoetal antigen tumour-targeted superantigen (ABR214936) therapy in patients with advanced renal cell carcinoma. Br J Cancer 96: 567-574, 2007.
32. Myers KA, Ryan MG, Shaw DM, Embleton MJ, Stern PL, Kingsman SM and Carroll MW: Tumour cell targeting of immune effector molecules using tumour associated antigen specific scFv fusion proteins. Cancer Gene Ther 9: 884-896, 2002.

33. Mamot C, Drummond DC, Noble CO, et al: Epidermal growth factor receptor-targeted immunoliposomes significantly enhance the efficacy of multiple anticancer drugs in vivo. Cancer Res 65: 11631-11638, 2005.

34. Mandler R, Kobayashi H, Hinson ER, Brechbiel MW and Waldmann TA: Herceptin-geldanamycin immunoconjugates pharmacokinetics, biodistribution, and enhanced antitumor activity. Cancer Res 64: 1460-1467, 2004.

35. Carsberg CJ, Myers KA and Stern PL: Metastasis-associated 5T4 antigen disrupts cell-cell contacts and induces cellular motility in epithelial cells. Int J Cancer 68: 84-92, 1996.

36. Awan A, Lucic MR, Shaw DM, Sheppard F, Westwater C, Lyons SA and Stern PL: 5T4 interacts with TIP-2/GIPC, a PDZ protein, with implications for metastasis. Biochem Biophys Res Commun 290: 1030-1036, 2002.

37. Hasson T: Myosin VI: two distinct roles in endocytosis. J Cell Sci 116: 3453-3461, 2003.

38. De Vries L, Elenko E, McCaffery M, et al: RGS-GAIP, a GTPase-activating protein for Gai3 heterotrimeric $G$ proteins, is located on Clathrin-coated vesicles. Mol Biol Cell 9: 1123-1134, 1998

39. De Vries L, Lou X, Zhao G, Zheng B and Farquhar M G: GIPC, a PDZ domain containing protein, interacts specifically with the C terminus of RGS-GAIP. Proc Natl Acad Sci USA 95: 12340-12345, 1998 . 